\title{
Adsorption of Polymeric Additives Based on Vinyl Acetate Copolymers as Wax Dispersant and Its Relevance to Polymer Crystallization Mechanisms
}

\author{
Ayman M. Atta, ${ }^{1,2}$ Rasha A. El-Ghazawy, ${ }^{2}$ Fatma A. Morsy, ${ }^{3}$ \\ Ali M. S. Hebishy, ${ }^{3}$ and Abdullah Elmorsy ${ }^{3}$ \\ ${ }^{1}$ Chemistry Department, College of Science, King Saud University, Riyadh 11451, Saudi Arabia \\ ${ }^{2}$ Petroleum Application Department, Egyptian Petroleum Research Institute, Nasr City, Cairo, Egypt \\ ${ }^{3}$ Chemistry Department, Faculty of Science, Helwan University, Helwan, Egypt
}

Correspondence should be addressed to Ayman M. Atta; aatta@ksu.edu.sa

Received 26 October 2014; Revised 13 March 2015; Accepted 1 April 2015

Academic Editor: Chao Jin

Copyright (C) 2015 Ayman M. Atta et al. This is an open access article distributed under the Creative Commons Attribution License, which permits unrestricted use, distribution, and reproduction in any medium, provided the original work is properly cited.

The present work has main target to study the effect of additives molecular weight and composition on the flow characteristics of wax crude oil at low temperature below pour point temperature. In this respect, maleic anhydride ester-co-vinyl acetate copolymers with varied monomers feed ratios and different alkyl ester lengths, namely, dodecyl, stearyl, and behenyl alkyl chains, were prepared. These polymeric materials were characterized by FTIR, ${ }^{1} \mathrm{HNMR}$, and GPC. The performance of these additives as pour point depressants and flow improver for Egyptian waxy crude oil was evaluated through measurements of pour point and rheological parameters (viscosity and yield stress). It was observed that stearyl maleate-vinyl acetate copolymer with $1: 2$ feed ratio shows the best efficiency as pour point depressant even at low concentration while octadecyl maleate-vinyl acetate copolymers with $2: 1$ feed ratio are effective as flow improver.

\section{Introduction}

The paraffin deposition formed during production and transportation of light crude oil and natural gases and condensates is one of the main problems that affect the oil productivity especially at low temperature [1-3]. The crude oil constituents have pronounced effect on its flow characteristics with variation of the surrounding temperature. Egyptian crude oil contains different amounts of paraffin wax depending on the field and area of production. At low temperatures, crude oil containing high amounts of paraffin shows high pour points due to paraffin deposition; that is, paraffins tend to crystallize forming wax crystals. The wax deposition is a result of cooling down the crude oil below certain temperatures during transportation or storage. This temperature depends upon the constituents of crude oil and is called pour point temperature (PPT) [4]. The wax deposit on the walls of the pipeline causes many serious problems such as decreasing the effective diameter of the pipeline and even pipeline blocking [5]. Thus, it is valuable from the economic point of view to minimize the effect of wax deposition. It is necessary to maintain the temperature of paraffin crude oil by insulation or heating which consumed more energy to prevent the crude oil treatments. The mechanical and thermal treatments have been used to control the paraffin deposition but these treatments consumed times and energy. The chemical treatments based on using pour point depressants, viscosity modifiers, flow improver, wax modifier, and asphaltene dispersant attracted great attention in oilfield chemicals to increase the oil transportation and productivity [6-9]. The literatures $[10,11]$ proved that these chemicals should have similar structure to paraffin to interact with paraffin and prevent their agglomeration in crude oils. Moreover, these additives should have polar functional groups to repulse each other to cocrystallize with paraffin and disperse them in crude oil.

Copolymerization is of great interest in synthesizing polymers with desired physical and chemical properties 
TABLE 1: The physicochemical properties of Norpetco crude oil.

\begin{tabular}{lcc}
\hline Test & Method & Result \\
\hline API gravity at 60 F & ASTM D-1298 & 41.1 \\
\hline Specific gravity at 60/60 F & ASTM D-1298 & 0.820 \\
\hline Wax content (wt\%) & UOP 46/64 & 8.4 \\
\hline Asphaltene content (wt\%) & IP 143/84 & 3 \\
\hline Water content (vol\%) & IP 74/70 & 0.23 \\
\hline Kinematic viscosity (cSt) at & & \\
$50^{\circ} \mathrm{C}$ & ASTM D-445 & 7 \\
$60^{\circ} \mathrm{C}$ & & 4.3 \\
\hline Pour point ${ }^{\circ} \mathrm{C}$ & QPC procedure & 30 \\
\hline
\end{tabular}

through controlling monomers ratio, their concentrations, and polymerization procedure. PPD is synthesized with two essential parts: oil soluble paraffinic chain and a polar moiety. The usefulness of paraffin chain is to cause nucleation and cocrystallization while the polar part controls the crystal growth and limits the size of wax crystals [12-15]. Vinyl acetate polymers such as vinyl acetate- $\alpha$-olefin [16], poly-n-alkyl acrylates $[1,2]$, and methacrylate copolymers [17-19] have been used to improve crude oil flowability. The application of pour point depressants has also been described in several patents [20,21]. More recently, pour point depressant effect on rheological behaviors of heavy and light Mexican crude oils was evaluated with various copolymers based on different combinations of vinyl acetate, styrene, and n-butyl acrylate [22]. This work aims to prepare vinyl acetate maleic anhydride copolymers having different monomer compositions using radical polymerization followed by esterification with different types of aliphatic alcohol to study the performance of the prepared copolymers as PPD additives for Egyptian waxy crude. Moreover, the efficiency of the prepared copolymers as flow improver was evaluated through rheology measurements of the treated crude oil. The effects of three modified polymers upon the deposition with a multicomponent wax of the tested crude oil were also investigated.

\section{Experimental}

2.1. Materials. Vinyl acetate, maleic anhydride, dodecyl alcohol (DA), stearyl alcohol (SA), behenyl alcohol (BA), benzoyl peroxide (BP), and P-toluene sulfonic acid monohydrate (PTSA) were purchased as analytical grade from Aldrich Chemicals Co., Germany. Benzene, dimethylformamide (DMF), and xylene were delivered from Adweic Chemicals Co., Egypt.

Egyptian waxy crude oil (Norpetco, Egypt) was delivered without treatment from Fardous field. The physicochemical characteristics and composition of Fardous mixed crude oils are listed in Table 1.

2.2. Copolymerization. Maleic anhydride-vinyl acetate copolymer was prepared by copolymerizing vinyl acetate (VA) and maleic anhydride (MA) in different molar feed ratios of VA:MA, namely, $1: 1,1: 2$, and $2: 1$, in reaction flask using dry benzene as solvent and $1 \%$ (wt/wt) benzoyl peroxide (BP) as initiator. The reaction proceeds for 6 hours at $60-$ $70^{\circ} \mathrm{C}$ with constant stirring under nitrogen atmosphere. After completion of polymerization, benzene was distilled off under vacuum. The copolymer was purified using benzene as solvent and petroleum ether as nonsolvent. The purified copolymer was dried at $60^{\circ} \mathrm{C}$ under vacuum.

2.3. Esterification. The reaction mixture containing $0.01 \mathrm{~mol}$ VA-MA copolymer solution in DMF, with one of the previously described molar ratios, and $0.02 \mathrm{~mol}$ of each alcohol (dodecyl, stearyl, or behenyl) was refluxed separately in presence of 0.1 (wt\%) PTSA as a catalyst. The reaction was carried out at the refluxing temperature until theoretical amount of water was collected azeotropically in the Dean Stark trap that contains small amount of toluene to determine the amount of produced water. The resulting esters were washed out with water to remove the catalyst and any unreacted materials.

The prepared esters, dodecyl maleate-vinyl acetate (VADM) copolymers, stearyl maleate-vinyl acetate (VASM) copolymers, and behenyl maleate-vinyl acetate (VABM) copolymers were purified and used as additives for crude oil.

2.4. Characterization. The carbon distribution number of separated wax was determined using GC-Mass spectrometer.

${ }^{1} \mathrm{H}$ NMR analysis were recorded on a Varian Gemini 2000 at $300 \mathrm{MHz}$ and Fourier transform infrared (FTIR, Perkin-Bhaskar-Elmer Co., USA) spectrometers were used to determine the chemical structures of copolymers.

The molecular weight data of the prepared copolymers, such as the weight average molecular weights $\left(M_{w}\right)$, the number average molecular weights $\left(M_{n}\right)$, and polydispersity index, were characterized using Shimadzu's gel permeation chromatograph equipped with refractive index detector and polydivinylbenzene mix gel-D column. Tetrahydrofuran (THF) with a flow rate of $1 \mathrm{~mL} / \mathrm{min}$ was used as mobile phase and polystyrene was used as the standard.

2.5. Evaluation Tests. Pour points measurements were determined using modified ASTM D-97 method without reheating to $45^{\circ} \mathrm{C}$ using different concentrations of the prepared additives, namely, 1000, 2000, 3000, 4000, and $5000 \mathrm{ppm}$. The effect of additive on the wax crystal morphologies was observed using an Olympus BX51 polarized-light microscope with a Linkam THMS 600 hot stage. The images were taken after transferring a small quantity of treated or untreated crude oil to glass slide inside a copper stage which has central window.

Viscosity and flow curves (rheogram) were measured using Brookfield viscometer equipped with thermostated cooling system for temperature adjustment [23]. Measurements were carried out at different temperatures below pour point of crude oils ranging from 21 to $12^{\circ} \mathrm{C}$ using $5000 \mathrm{ppm}$ of each additive separately.

The yield stress measurements were determined from the relationship between shear stress and shear rate valued measured using Brookfield viscometer. Oil samples with or without additives were heated to $80^{\circ} \mathrm{C}$, with the temperature 


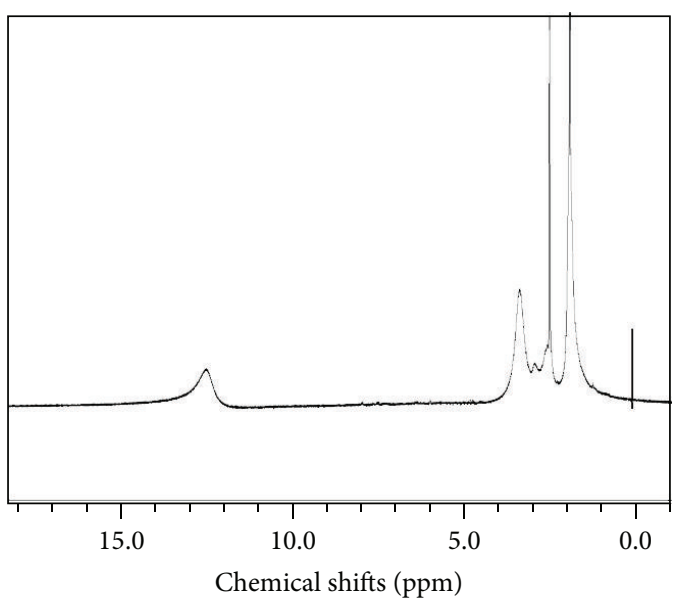

(a)

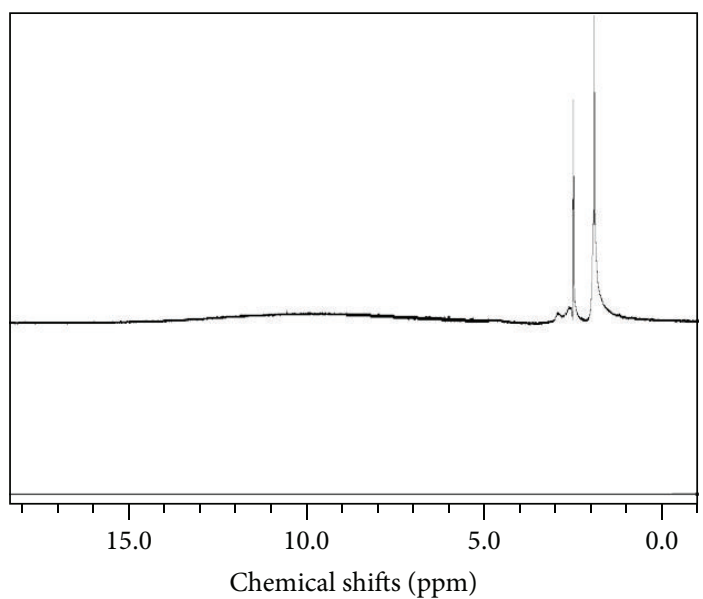

(b)

FIGURE 1: ${ }^{1}$ HNMR spectra of VA : MA having monomer feed compositions (a) (1:2) and (b) $(1: 1)$.

maintained for $5 \mathrm{~min}$ to adopt their thermal history. The temperature decreased by $10^{\circ} \mathrm{C} / \mathrm{min}$ cooling rate to the experimental test temperature. The test temperature was determined from pour point measurements for both the crude oils and treated crude oils. The viscosity values were measured, after annealing the sample at the measurement temperature without shear for $5 \mathrm{~min}$, by applying stress and incrementally increased every $10 \mathrm{~s}$ (100 stress increments per decade). The yield stress is defined as the stress below which no flow occurs.

\section{Result and Discussion}

Polymers including vinyl acetate (VA) and alkyl acrylate are used mainly as additives to improve the flow ability of waxy crude oil at low temperature. It is presumed that effective additives should match crude wax in structure, composition, and content. In this respect, we select vinyl acetate and maleic anhydride to prepare polymeric additives for Egyptian waxy crude oil. The main idea depends on variation of copolymer compositions by changing the monomer feed composition of VA:MA as $1: 1,1: 2$, and $2: 1$ followed by esterification with different types of n-alkanol such as dodecyl, stearyl, or behenyl alcohol. The chemical structure was designed on the previous results showing that VA copolymers containing from 20 to $40 \% \mathrm{w} / \mathrm{w}$ of vinyl acetate performed well when applied in some petroleum samples $[1,2]$. Moreover, VA copolymers containing long side chains (from $\mathrm{C}_{12}$ to $\mathrm{C}_{18}$ ) have also presented good performance for other kinds of oil [24].

${ }^{1}$ HNMR spectra of maleic anhydride-vinyl acetate copolymer with different monomer feed composition are presented in Figure 1. The spectra show different chemical shifts at about $1.8 \mathrm{ppm}$ for methyl protons, $2.4 \mathrm{ppm}$ for methyl protons adjacent to ( $\mathrm{C}=\mathrm{O}$ group $)$ in VA moieties, and $3.5 \mathrm{ppm}$ for $\mathrm{CH}$ protons adjacent to the acetate group in VA moieties. The disappearance of vinyl group peaks in the range of chemical shift 4.5-6.5 ppm indicates polymerization of VA and MA. The appearance of peak at $12 \mathrm{ppm}$ indicated the
TABLE 2: The average molecular weight of the prepared copolymer at different mole ratios.

\begin{tabular}{lccc}
\hline \multirow{2}{*}{ Polymer composition } & \multicolumn{3}{c}{ Molecular weight $(\mathrm{g} / \mathrm{mol})$} \\
& $M_{w}$ & $M_{n}$ & PD \\
\hline VA-MA $(1: 1)$ & $1.13 \times 10^{4}$ & $3.5 \times 10^{3}$ & 3.22 \\
VA-MA $(1: 2)$ & $1.7 \times 10^{4}$ & $4.7 \times 10^{3}$ & 3.61 \\
VA-MA $(2: 1)$ & $9.65 \times 10^{3}$ & $6.03 \times 10^{3}$ & 1.6 \\
\hline
\end{tabular}

conversion of anhydride group to $\mathrm{COOH}$ groups for VA-MA copolymer compositions $2: 1$ and $1: 2$. Here, a conversion near $100 \%$ was determined by gravimetric measurements.

Molecular weights of the prepared polymers with the different feed ratios were determined using gel permeation chromatography (GPC) using THF as eluent and the results are summarized in Table 2. The molecular weight results indicated that the molecular weight slightly increase by increasing the maleic anhydride content.

3.1. Esterification of VA-MA Copolymers. Through this paper, three VA-MA copolymers were reacted with alkanol having different alkyl length using esterification reaction as illustrated in Scheme 1. The alkyl group introduced in VA-MA copolymers was used to increase the solubility of esterified copolymers in toluene and crude oil. The chemical structure of the esterified copolymer was confirmed by FTIR spectroscopy. In this respect, FTIR spectrum of VADM was selected as representative sample and represented in Figure 2. The FTIR spectrum shows strong absorption bands at $1745 \mathrm{~cm}^{-1}$ (indicating the presence of $\mathrm{C}=\mathrm{O}$ ester group) and disappearance of bands at about 1810 and $1780 \mathrm{~cm}^{-1}$ and $3500 \mathrm{~cm}^{-1}$ which is attributed to $\mathrm{C}=\mathrm{O}$ stretching vibration of anhydride and $\mathrm{OH}$ of carboxylic maleic groups, respectively. $3080-3150 \mathrm{~cm}^{-1}$ indicates the complete esterification of VAMA copolymers [25].

In addition, the chemical structure of esterified VA-MA copolymers was confirmed by ${ }^{1} \mathrm{HNMR}$. Figure 3 represents 


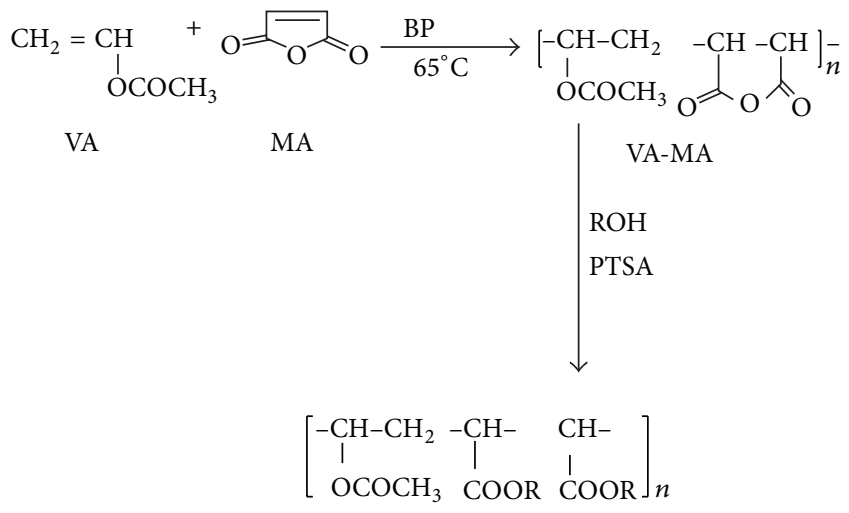

$\begin{array}{ll}\mathrm{R}=\mathrm{C}_{12} \mathrm{H}_{25} & \text { VADM } \\ \mathrm{R}=\mathrm{C}_{18} \mathrm{H}_{37} & \text { VASM } \\ \mathrm{R}=\mathrm{C}_{22} \mathrm{H}_{45} & \text { VABM }\end{array}$

SCHEME 1: Synthesis of VA-MA ester copolymers.

the ${ }^{1}$ HNMR spectra of VADM, VASM, and VABM esters of VA-MA (1:2). Molecular characterization of the esterified copolymers was determined using the method outlined by Thamizharasi et al. [26] where a comparison of the intensity of some selected peaks was held to determine the copolymer compositions. The relative peak intensities were determined from peak areas calculated by means of electronic integration. In this respect, we select peaks at $12 \mathrm{ppm}$ (attributed to $\mathrm{COOH}$ protons) and new peak observed at $3.9 \mathrm{ppm}$ (referring to $\mathrm{CH}_{2}$ protons attached to $\mathrm{COO}$ of MA group) to confirm the esterification of VA-MA copolymers. The data indicate efficient esterification reaction of VA-MA copolymers with SA more than both BA and DA. The data indicated that the esterification of VA-MA with SA, DA, and BA was 100, 80, and $55 \%$, respectively. This may be attributed to the difference in polarity and compatibility between the reactants, a factor that would affect the reactivity of the functional groups [27-29].

\subsection{The Influence of Additive on Pour Point of Crude Oil.} It is common that all waxy crude oils eventually become nonfluid on chilling [30]. This is related to precipitation of wax crystals by chilling which interlock to form threedimensional network. PPD are especially designed substance having hydrophobic moieties to change the rheology of crude oil and to facilitate the flow problems [31]. The efficiency of any polymeric additive used as pour point depressant is attributed to its ability to disperse the paraffin wax. It was previously reported that [32] the polymeric additives should have hydrophobic side chains and have strong interactions with crude oil to reduce their viscosity and enhance their ability to flow. Moreover, the average molecular weight distribution of additives should have broad distribution to cover the nparaffin distribution. In addition, the performance of PPD depends on the characteristics of crude oil itself including total wax content, the chain length and shape (linear or branched), and quantity and type of wax present in crude [33]. In this respect, urea adduction method is used to isolate paraffin from crude oil to be analyzed with GLC as described
TABLE 3: The pour point of untreated crude oil and treated crude oil with VADM.

\begin{tabular}{lcccccc}
\hline \multirow{2}{*}{$\begin{array}{l}\text { Copolymer } \\
\text { composition }\end{array}$} & \multicolumn{7}{c}{$\begin{array}{c}\text { Pour point temperature }\left({ }^{\circ} \mathrm{C}\right) \\
\text { at concentrations (ppm) }\end{array}$} \\
& Nil & 1000 & 2000 & 3000 & 4000 & 5000 \\
\hline $\operatorname{VADM~}(1: 1)$ & 30 & 27 & 24 & 21 & 21 & 18 \\
$\operatorname{VADM}(1: 2)$ & 30 & 30 & 27 & 24 & 24 & 21 \\
$\operatorname{VADM}(2: 1)$ & 30 & 30 & 27 & 24 & 24 & 21 \\
\hline
\end{tabular}

TABLE 4: The pour point of untreated crude oil and treated crude oil with VASM.

\begin{tabular}{lcccccc}
\hline \multirow{2}{*}{$\begin{array}{l}\text { Copolymer } \\
\text { composition }\end{array}$} & \multicolumn{5}{c}{$\begin{array}{c}\text { Pour point temperature }\left({ }^{\circ} \mathrm{C}\right) \\
\text { at concentrations }(\mathrm{ppm})\end{array}$} \\
& Nil & 1000 & 2000 & 3000 & 4000 & 5000 \\
\hline $\operatorname{VASM}(1: 1)$ & 30 & 27 & 27 & 27 & 27 & 24 \\
$\operatorname{VASM}(1: 2)$ & 30 & 15 & 15 & 12 & 12 & 12 \\
$\operatorname{VASM}(2: 1)$ & 30 & 15 & 15 & 15 & 15 & 12 \\
\hline
\end{tabular}

in the Experimental. The n-paraffin is determined as $12 \mathrm{wt} . \%$ from urea adduct method. Further analysis of $n$-paraffins by GLC for Norpetco crude oil was carried out to determine the carbon numbers as shown in Figure 4.

From data represented in Figure 4, the total carbon average of paraffin is 44 with broad molecular weight distribution. This means that the $\mathrm{n}$-paraffin with $\mathrm{C}-44$ tends to form precipitate and block the crude oil flow by forming interlocking networks. Accordingly, the side chains of polymers should have lengths resembling paraffin wax distributions to interact with paraffin and inhibit the formation of wax networks. The structure and composition of flow improvers should possess high polar functional groups such as amide, ester, amine, and hydroxyl groups. When an additive contains both long-chain hydrocarbon and polar moieties, it may be efficient as wax dispersant and flow improver. The mechanism of pour point depression has been well explained [34]; the PPD in crude oil changes the wax crystal shapes from extensively interlocking plates to more compact crystals by cocrystallizing with the wax. The more similar the polymer structure to wax components, the better its performance and the better its ability to attach to wax components and create a barrier for networking of wax particles.

The evaluation of the prepared copolymer esters as PPD was studied through preparation of crude oil samples treated with different concentrations from each additive, namely, $1000,2000,3000,4000$, and $5000 \mathrm{ppm}$. The results of pour point measurement are given in Tables 3,4 , and 5 . The pour point data, given in Tables 3-5, show that the length of the alkyl chain affects the efficiency of polymeric additives. Generally, the most effective additives are the VASM and VADM showing a maximum of $9^{\circ} \mathrm{C}$ depression in pour point only at high dose of additive $(5000 \mathrm{ppm})$, that is, low effectiveness as PPD, while in VASM the extent of depression in pour point reaches about $18^{\circ} \mathrm{C}$ at the same dose $(5000 \mathrm{ppm})$. These results of pour point also showed that VASM with mol ratio $(1: 2)$ are the most efficient PPD. 


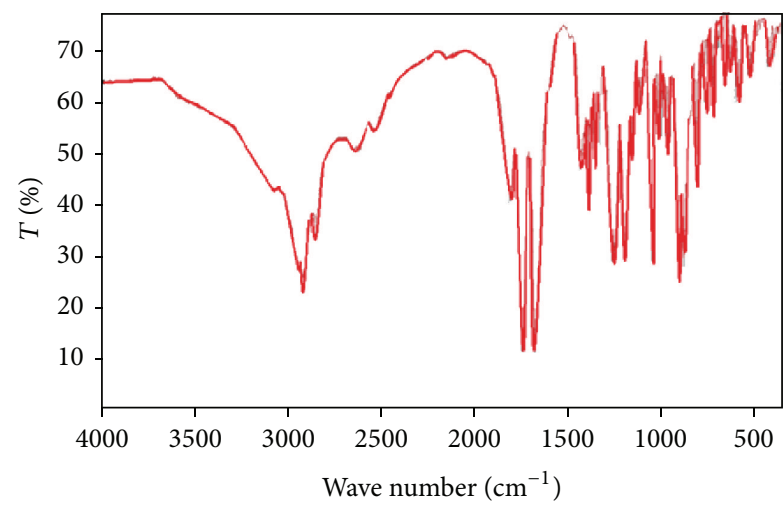

(a)

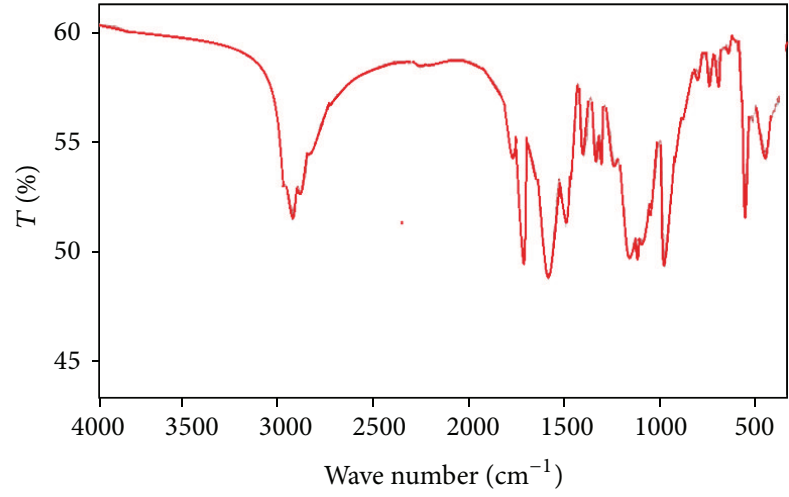

(b)

Figure 2: FTIR spectra of (a) VA-MA and (b) VADM copolymers.

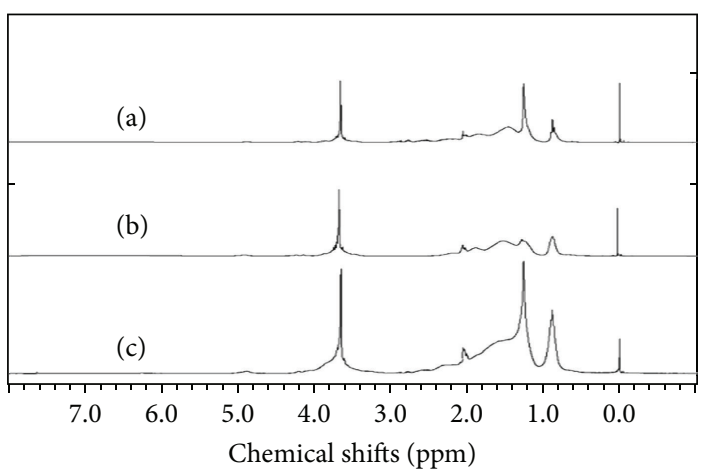

Figure 3: ${ }^{1}$ HNMR spectra of (a) VASM, (b) VADM, and (c) VABM copolymers.

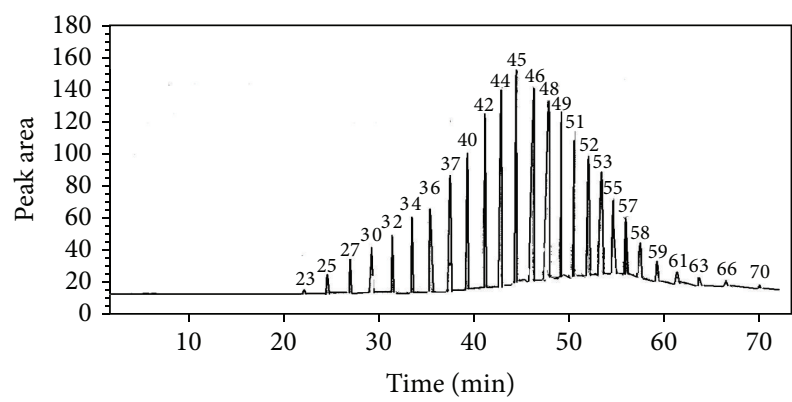

Figure 4: Chromatogram of paraffins extracted from Norpetco crude oil.

The higher efficiency of these esters can be correlated to the presence of higher alkyl side chain and to the percentage of esterification to VA content. This additive contains the highest maleic anhydride content and thus high dispersing activity as a result of combined effect of carbonyl oxygen of maleic anhydride and the polarity exerted by methoxy group in the polymers. However, regarding the performance of VABM, they do not show noticeable effect as PPD for this crude oil; this can be rationalized by the increased chain length which renders the polymer more bulky and less soluble
TABLE 5: The pour point of untreated crude oil and treated crude oil with VABM.

\begin{tabular}{lcccccc}
\hline $\begin{array}{l}\text { Copolymer } \\
\text { composition }\end{array}$ & \multicolumn{7}{c}{$\begin{array}{c}\text { Pour point temperature }\left({ }^{\circ} \mathrm{C}\right) \\
\text { at concentrations (ppm) }\end{array}$} \\
& Nil & 1000 & 2000 & 3000 & 4000 & 5000 \\
\hline $\operatorname{VABM~}(1: 1)$ & 30 & 30 & 30 & 27 & 27 & 27 \\
$\operatorname{VABM}(1: 2)$ & 30 & 30 & 30 & 27 & 27 & 24 \\
$\operatorname{VABM}(2: 1)$ & 30 & 30 & 27 & 27 & 27 & 24 \\
\hline
\end{tabular}

making it less effective. In other words, VABM may itself deposit acting as a nucleus for deposition of paraffin wax of crude oil.

The microscopic images of untreated and treated Norpetco crude oil with $5000 \mathrm{ppm}$ of VASM $(1: 2)$ at the pour point temperature are shown in Figures 5(a) and 5(b). The wax crystals of untreated crude oil appeared agglomerated thin and feather-shaped which indicates the growth of wax crystals at nucleating sites (Figure 5(a)). These agglomerates will import high surface energy to untreated crude oil and tend to interconnect into a three-dimensional network structure. This interaction increased the pour point of untreated crude oil. However, the addition of 5000 ppm VASM $(1: 2)$ modifies the crystal structure to globular morphologies (Figure 5(b)).

3.3. The Impact of Additives on Rheology of Crude Oil. The rheology is used to evaluate the crude oil flow ability in the absence and presence of the prepared polymeric additives. The rheological parameters for untreated and treated crude oil with $5000 \mathrm{ppm}$ of VASM were determined at different temperatures, namely, $12^{\circ} \mathrm{C}, 15^{\circ} \mathrm{C}$, and $21^{\circ} \mathrm{C}$. Figures 6,7 , and 8 represent variation of shear stress as a function of shear rate. The Bingham plastic flow model is illustrated by the following equation: Shear stress $(\mathrm{Pa})=$ Yield stress $(\mathrm{Pa})+$ Shear rate $\left(S^{-1}\right) \times$ plastic viscosity $(\mathrm{mPas})$. The yield stress values of the treated crude oil in presence of $5000 \mathrm{ppm}$ of VASM additives with different composition are displayed in Table 6 . The data show that the tested crude oils possess high yield shear stress values at low temperature at and below their pour points. On 


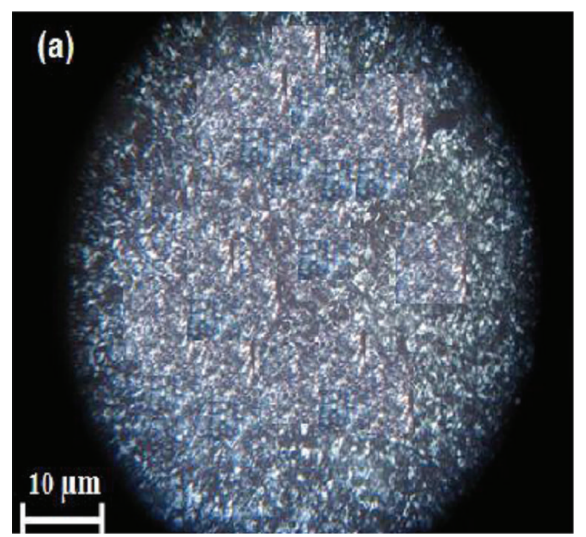

(a)

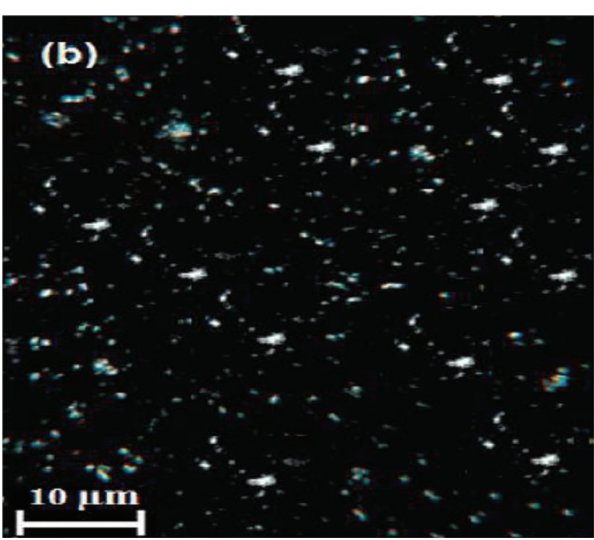

(b)

FIGURE 5: Polarized microscopic image morphologies of (a) untreated and (b) treated Norpetco crude oils with 5000 ppm of VASM (1:2) at their pour point temperatures.

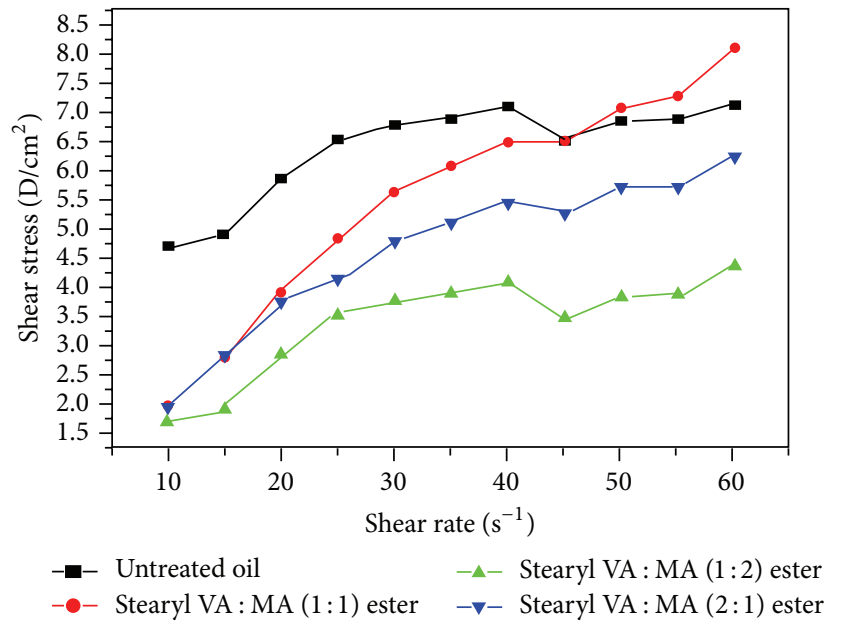

FIGURE 6: Rheogram of untreated and treated crude oil with $5000 \mathrm{ppm}$ of different mol ratios at $12^{\circ} \mathrm{C}$.

the other hand, it was observed that the viscosity of crude oils was increased with cooling. Therefore, the high wax content leads to the formation of gelled crude at low temperatures due to the crystallization of the wax which in turn affects the viscosity of crude oils.

Moreover, the long-chain alkyl grafts in VASM $(2: 1)$ have the same effect on the long-chain paraffins in the distribution of wax and paraffin in the crude oil. The possible reason for lowering the yield stress and pour point temperature is attributed to match of side alkyl chain length with the paraffin length of the tested crude oil. Moreover, the molecular weight of alkyl substituent has strong effect on the solubility of the additives in the crude oil. It is found that the VAMA $(2: 1)$ ester copolymers have low polydisperse molecular weights and have moderate high molecular weight (Table 2), achieving the best low pour point temperature and yield stress results (Tables 3-6). This behavior was attributed to the effect of polymer molecular weights on the polymer radius of gyration and hence on the viscosity [24].

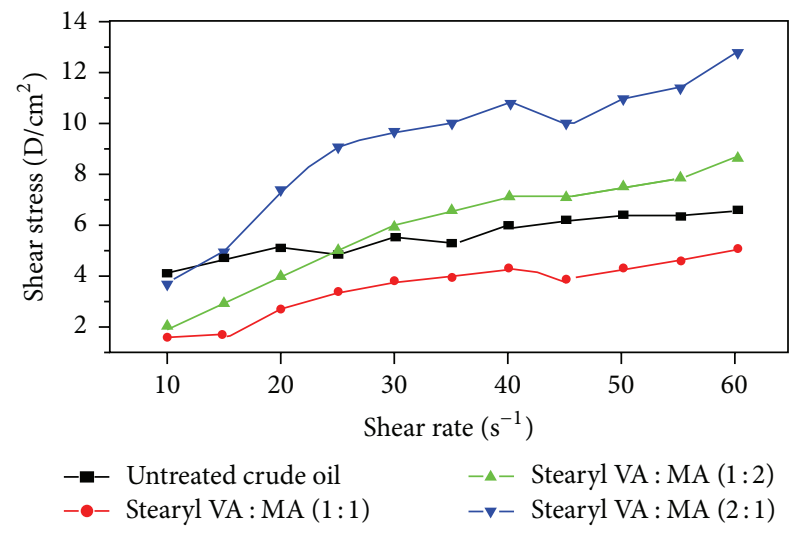

FIGURE 7: Rheogram of untreated and treated crude oil with $5000 \mathrm{ppm}$ of different mol ratios at $15^{\circ} \mathrm{C}$.

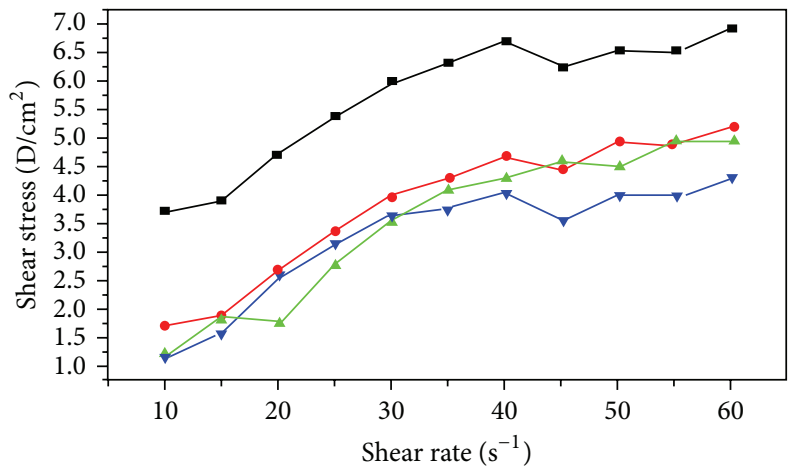

--- Untreated crude oil - - - Stearyl VA : MA $(1: 2)$ ester

-•- Stearyl VA : MA $(1: 1)$ ester $\quad-\nabla-$ Stearyl VA : MA $(2: 1)$ ester

FIGURE 8: Rheogram of untreated and treated crude oil with $5000 \mathrm{ppm}$ of different mol ratios at $21^{\circ} \mathrm{C}$.

The apparent viscosities $(\mathrm{mPaS})$ of the untreated and treated crude oils with VASM $(2: 1)$ were determined at different temperatures to evaluate the effect of the polymer 
TABLE 6: Yield value of untreated and treated crude oil with $5000 \mathrm{ppm}$ concentration of the additives of different composition.

\begin{tabular}{lcc}
\hline Oil sample & $T\left({ }^{\circ} \mathrm{C}\right)$ & Yield value $\left(\mathrm{Dyne} / \mathrm{cm}^{2}\right)$ \\
\hline \multirow{3}{*}{ Untreated } & 12 & 4.89 \\
& 15 & 3.93 \\
& 21 & 3.52 \\
\hline \multirow{2}{*}{ VASM $(1: 1)$} & 12 & 1.57 \\
& 15 & 1.36 \\
& 21 & 1.34 \\
VASM $(1: 2)$ & 12 & 1.83 \\
& 15 & 1.56 \\
& 21 & 1.19 \\
VASM $(2: 1)$ & 12 & 1.99 \\
& 15 & 1.50 \\
& 21 & 1.30 \\
\hline
\end{tabular}

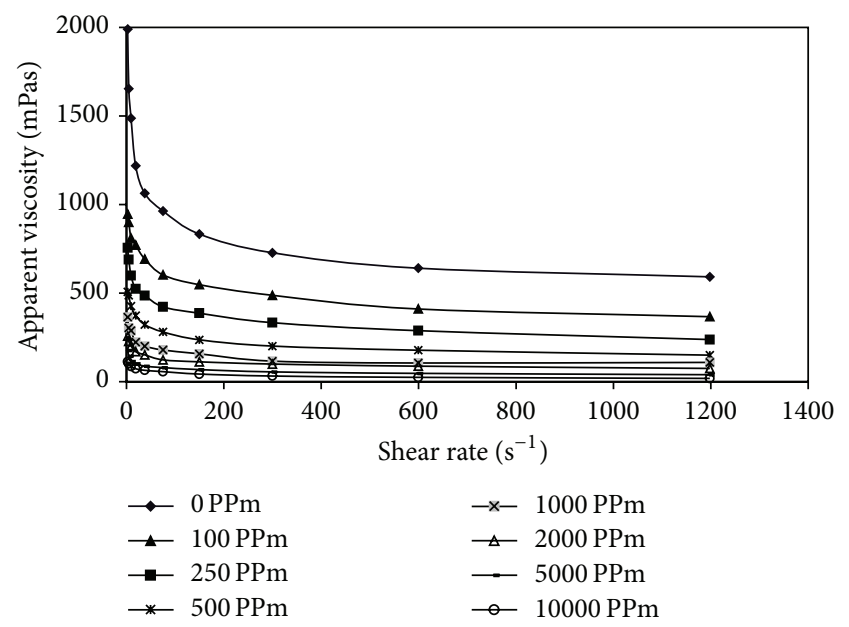

Figure 9: Effect of VASM $(2: 1)$ on the apparent viscosity on Norpetco crude oil at $15^{\circ} \mathrm{C}$.

on the viscosities of Norpetco crude (representative samples are shown in Figure 9).

The values of the plastic viscosity $(\mathrm{mPaS})$ and yield shear stress values $(\mathrm{Pa})$ decreased by the addition of VASM $(2: 1)$ additives even at high concentrations (10,000 ppm). Figure 9 shows the variation of crude oil viscosity as a function of copolymer concentration at $15^{\circ} \mathrm{C}$. It can be observed that high concentration of copolymer can effectively reduce the crude oil viscosity. In absence of PPD additives at this temperature range (below PPT of blank crude sample), paraffin crystals would be formed in the liquid media causing a non-Newtonian behavior of the oil. Upon treating crude samples with VASM $(2: 1)$ additives, Newtonian behavior can be observed even at this low temperature $\left(15^{\circ} \mathrm{C}\right)$ for all tested crude oil samples at $10,000 \mathrm{ppm}$. This indicates that $\operatorname{VASM}(2: 1)$ copolymer has the ability to disperse wax crystals and improve the flow behaviors of the tested crude oils as observed from the data listed in Table 6. These results are in good agreement with data on the polymeric additives [35-38] which decreased both pour point temperatures and the yield shear stress. Finally we can conclude that the VASM $(2: 1)$ can act as flow improver for Egyptian waxy crude oils.

\section{Conclusions}

The new hydrophobically modified VASM copolymers achieve efficient PPD for the Egyptian waxy crude oil. The effective concentration of PPD to inhibit the wax deposition, to decrease the pour point temperature, and to improve the rheological characteristics of crude oils was found to be 100$10000 \mathrm{ppm}$. The composition of VASM greatly affects the performance of the additive with the copolymer VASM with mole ratio $1: 2$ which is the most efficient additive in pour point depression, while the copolymer VASM with mole ratio $2: 1$ was the best additive in improving the crude oil yield shear stress and improving the flow properties of crude oil.

\section{Conflict of Interests}

The authors declare that there is no conflict of interests regarding the publication of this paper.

\section{Acknowledgment}

The authors extend their appreciation to the Deanship of Scientific Research at King Saud University for funding this work through Research Group no. RGP-VPP-235.

\section{References}

[1] A. L. C. Machado and E. F. Lucas, "The influence of vinyl acetate content of the poly(ethylene-co-vinyl acetate) (EVA) additive on the viscosity and the pour point of a Brazilian crude oil," Petroleum Science and Technology, vol. 19, no. 1-2, pp. 197-204, 2001.

[2] A. L. C. Machado, E. F. Lucas, and G. González, "Poly(ethyleneco-vinyl acetate) (EVA) as wax inhibitor of a Brazilian crude oil: oil viscosity, pour point and phase behavior of organic solutions," Journal of Petroleum Science and Engineering, vol. 32, no. 2-4, pp. 159-165, 2001.

[3] R. Hoffmann and L. Amundsen, "Influence of wax inhibitor on fluid and deposit properties," Journal of Petroleum Science and Engineering, vol. 107, pp. 12-17, 2013.

[4] A. E. Erceg Kuzmić, M. Radošević, G. Bogdanić, V. Srića, and R. Vuković, "Studies on the influence of long chain acrylic esters polymers with polar monomers as crude oil flow improver additives," Fuel, vol. 87, no. 13-14, pp. 2943-2950, 2008.

[5] H. P. Soni, D. P. Bharambe, and A. Nagar, "Synthesis of chemical additives and their effect on Akholjuni crude oil (Gujarat, India)," Indian Journal of Chemical Technology, vol. 12, no. 1, pp. 55-61, 2005.

[6] A. Uhde and G. Kopp, "Pipelines problems resulting from the handling of waxy crude oils," Journal of the Institute of Petroleum, vol. 57, pp. 63-73, 1971.

[7] R. A. Vora and D. P. Bharambe, "Polymeric flow improvers," Indian Journal of Technology, vol. 31, pp. 633-635, 1993.

[8] A. J. Son, R. B. Graugnard, B. J. Chai, and A. J. Son, “The effect of structure on performance of maleic anhydride copolymers as flow improvers of paraffinic crude oil," in Proceedings of the SPE International Symposium on Oil Field Chemistry, 25186, pp. 351-362, New Orleans, Lo, USA, 1993. 
[9] B. F. Towler and S. Rebbapragada, "Mitigation of paraffin wax deposition in cretaceous crude oils of Wyoming," Journal of Petroleum Science and Engineering, vol. 45, no. 1-2, pp. 11-19, 2004.

[10] A. Borthakur, N. C. Laskar, R. K. Mazumdar, K. V. Rao, and B. Subrahmanyam, "Synthesis and evaluation of alkyl fumaratevinyl acetate copolymers in combination with alkyl acrylates as flow improvers for Borholla crude oil," Journal of Chemical Technology and Biotechnology, vol. 62, no. 1, pp. 75-80, 1995.

[11] G. A. Holder and J. Winkler, "Crystal-growth poisoning of nparaffin wax by polymeric additives and its relevance to polymer crystallization mechanisms," Nature, vol. 207, no. 4998, pp. 719721, 1965.

[12] S. L. Wang, A. Flamberg, and T. Kikabhai, "Select the optimum pour point depressant," Hydrocarbon Processing, vol. 78, no. 2, pp. 59-62, 1999.

[13] D. Chanda, A. Sarmah, A. Borthakur, K. V. Rao, B. Subrahmanyam, and H. C. Das, "Combined effect of asphaltenes and flow improvers on the rheological behaviour of Indian waxy crude oil," Fuel, vol. 77, no. 11, pp. 1163-1167, 1998.

[14] D. M. Duffy and P. M. Rodger, "Hydrogen bonding and the conformations of poly(alkyl acrylamides)," Journal of the American Chemical Society, vol. 124, no. 18, pp. 5206-5212, 2002.

[15] A. G. Didukh, R. B. Koizhaiganova, L. A. Bimendina, and S. E. Kudaibergenov, "Synthesis and characterization of novel hydrophobically modified polybetaines as pour point depressants," Journal of Applied Polymer Science, vol. 92, no. 2, pp. 1042-1048, 2004.

[16] H. H. Abou El-Naga, W. M. Abd El-Azim, and M. M. Ahmed, "Polymeric additives for pour point depression of residual fuel oils," Journal of Chemical Technology and Biotechnology, vol. 35, no. 5, pp. 241-247, 1985.

[17] I. M. El-Gamal, A. M. Atta, and A. M. Al-Sabbagh, "Polymeric structures as cold flow improvers for waxy residual fuel oil," Fuel, vol. 76, no. 14-15, pp. 1471-1478, 1997.

[18] K. S. Pedersen and H. P. Rønningsen, "Influence of wax inhibitors on wax appearance temperature, pour point, and viscosity of waxy crude oils," Energy \& Fuels, vol. 17, no. 2, pp. 321-328, 2003.

[19] Y. Song, T. H. Ren, X. S. Fu, and X. H. Xu, "Study on the relationship between the structure and activities of alkyl methacrylatemaleic anhydride polymers as cold flow improvers in diesel fuels," Fuel Processing Technology, vol. 86, no. 6, pp. 641-650, 2005.

[20] W. Ahlers, A. Fechtenkotter, F. O. Mahling, I. Trotsch-Schaller, and A. Eisenbeis, "Fuel oil compositions with improved cold flow properties," US Patent Application 20070094920, 2007.

[21] R. A. Bloch and D. J. Martella, "Carboxylate-vinyl ester copolymer blend compositions for lubricating oil flow improvement," US. Patent no. 6475963, 2002.

[22] L. V. Castro and F. Vázquez, "Copolymers as flow improvers for Mexican crude oils," Energy and Fuels, vol. 22, no. 6, pp. 40064011, 2008.

[23] H. P. Ronningsen, B. Bjoerndal, A. B. Hansen, and W. B. Pedersen, "Wax precipitation from north sea crude oils. 1. Crystallization and dissolution temperatures, and Newtonian and non-Newton flow properties," Energy \& Fuels, vol. 5, pp. 895908, 1991.

[24] C. X. Da Silva, D. R. S. Álvares, and E. F. Lucas, "New additives for the pour point reduction of petroleum middle distillates," Energy \& Fuels, vol. 18, no. 3, pp. 599-604, 2004.
[25] H. P. Soni, K. S. Agrawal, A. Nagar, and D. P. Bharambe, "Designing maleic anhydride- $\alpha$-olifin copolymeric combs as wax crystal growth nucleators," Fuel Processing Technology, vol. 91, no. 9, pp. 997-1004, 2010.

[26] S. Thamizharasi, P. Gnanasundaram, and S. Balasubramanian, "Copolymers of 4-nitrophenyl methacrylate with styrene: synthesis, characterization, and reactivity ratios," Journal of Applied Polymer Science, vol. 74, no. 5, pp. 1186-1193, 1999.

[27] A. M. Atta, A. M. Elsayed, and H. I. Shafy, "Uses of electronbeam irradiation to prepare $\mathrm{pH}$ - And temperature-sensitive hydrogels from reactive poly(vinyl alcohol) grafts," Journal of Applied Polymer Science, vol. 108, no. 3, pp. 1706-1715, 2008.

[28] A. M. Atta, M. A. Elsockary, O. F. Kandil, and Z. M. Mohamed, "Using of modified plastic waste based on poly(ethylene-coacrylic acid) grafts to solve transportation problem of petroleum crude oil," Journal of Dispersion Science and Technology, vol. 29, no. 1, pp. 7-19, 2008.

[29] B. Wesslen and K. B. Wesslen, "Preparation and properties of some water-soluble, comb-shaped, amphiphilic polymers," Journal of Polymer Science, Part A: Polymer Chemistry, vol. 27, no. 12, pp. 3915-3926, 1989.

[30] S. Deshmukh and D. P. Bharambe, "Synthesis of polymeric pour point depressants for Nada crude oil (Gujarat, India) and its impact on oil rheology," Fuel Processing Technology, vol. 89, no. 3, pp. 227-233, 2008.

[31] H. S. Ashbaugh, L. J. Fetters, D. H. Adamson, and R. K. Prud'homme, "Flow improvement of waxy oils mediated by self-aggregating partially crystallizable diblock copolymers," Journal of Rheology, vol. 46, no. 4, pp. 763-776, 2002.

[32] J. Au, "Optimize pour point control to save money," Hydrocarbon Processing, vol. 80, no. 1, pp. 73-75, 2001.

[33] A. Borthakur, N. C. Laskar, R. K. Mazumdar, K. V. Rao, and B. Subramanyam, "Synthesis and evaluation of alkyl fumaratevinyl acetate copolymers in combination with alkyl acrylates as flow improvers for Borholla crude oil," Journal of Chemical Technology and Biotechnology, vol. 62, pp. 75-80, 1995.

[34] G. A. Holder and J. Winkler, "Wax crystallization from distillate fuels, part I. Cloud and pour phenomena exhibited by solutions of binary N-paraffin mixtures," J. Inst. Pet, vol. 51, pp. 228-232, 1965.

[35] S. E. Kudaibergenov, A. G. Didukh, Z. E. Ibraeva et al., "A regular, hydrophobically modified polyampholyte as novel pour point depressant," Journal of Applied Polymer Science, vol. 98, no. 5, pp. 2101-2108, 2005.

[36] H. Li and J. Zhang, "A generalized model for predicting nonNewtonian viscosity of waxy crudes as a function of temperature and precipitated wax," Fuel, vol. 82, no. 11, pp. 1387-1397, 2003.

[37] J. W. Qian, G. R. Qi, X. Z. Ding, and S. L. Yang, "Assessment of polymer flow improvers for crude oil by viscometry," Fuel, vol. 75, no. 3, pp. 307-312, 1996.

[38] H. P. Rønningsen, "Rheological behaviour of gelled, waxy North Sea crude oils," Journal of Petroleum Science and Engineering, vol. 7, no. 3-4, pp. 177-213, 1992. 

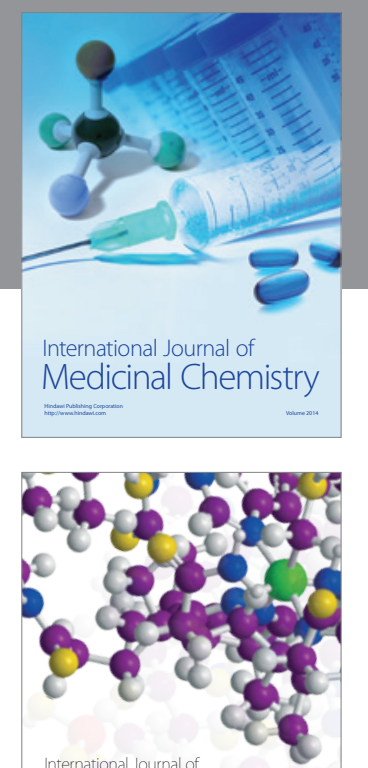

\section{Carbohydrate} Chemistry

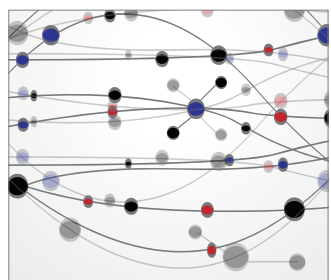

The Scientific World Journal
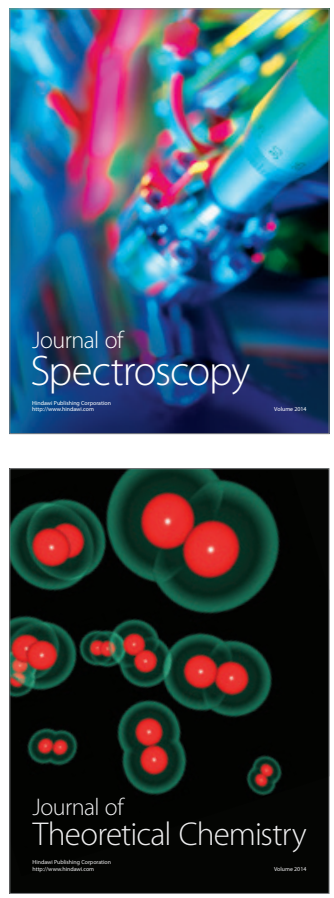
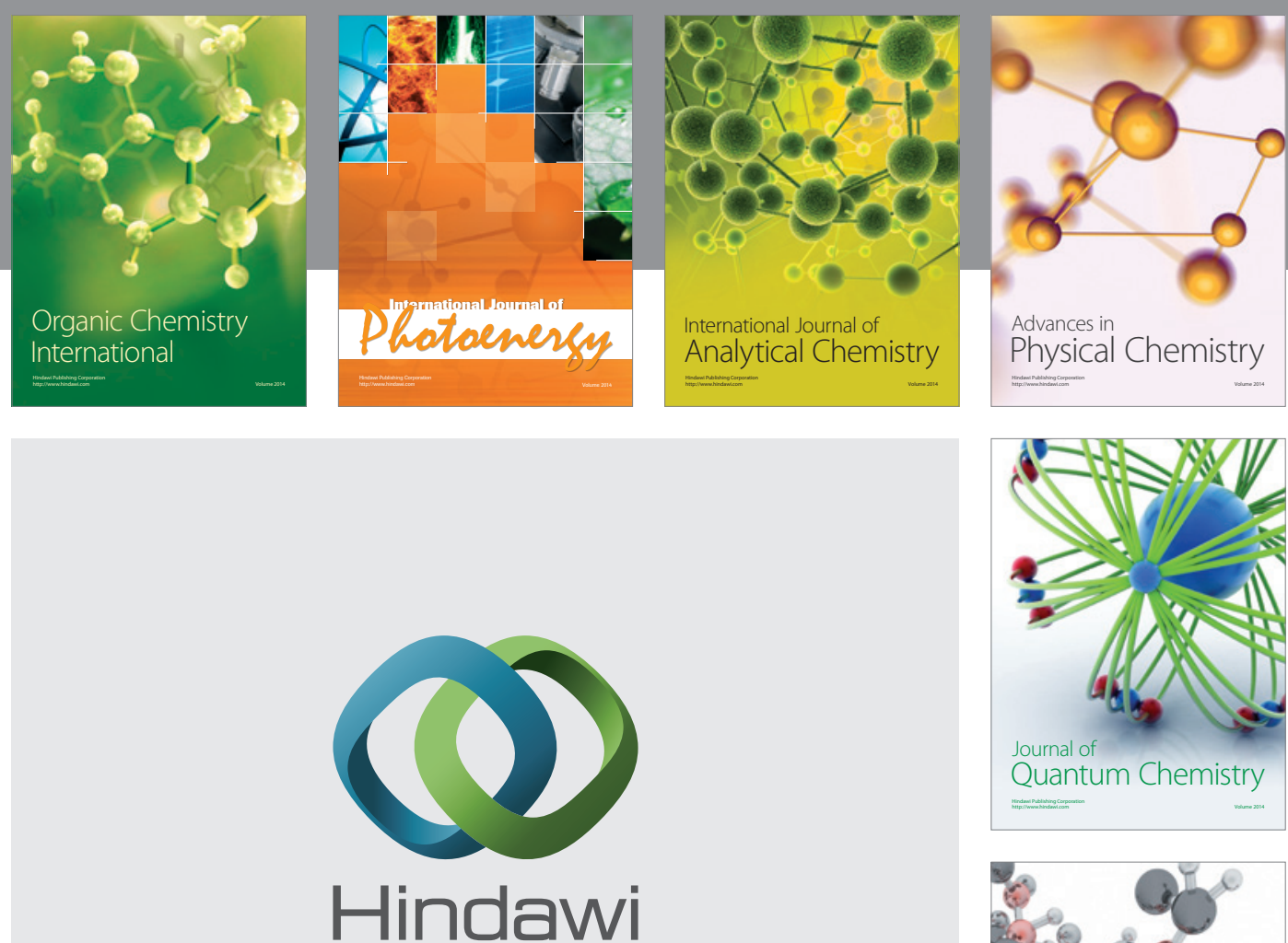

Submit your manuscripts at

http://www.hindawi.com

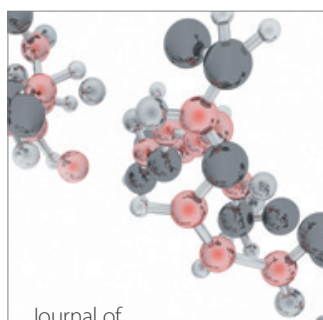

Analytical Methods

in Chemistry

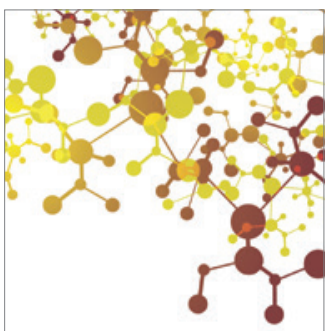

Journal of

Applied Chemistry

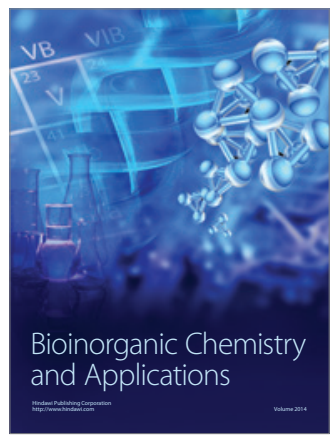

Inorganic Chemistry
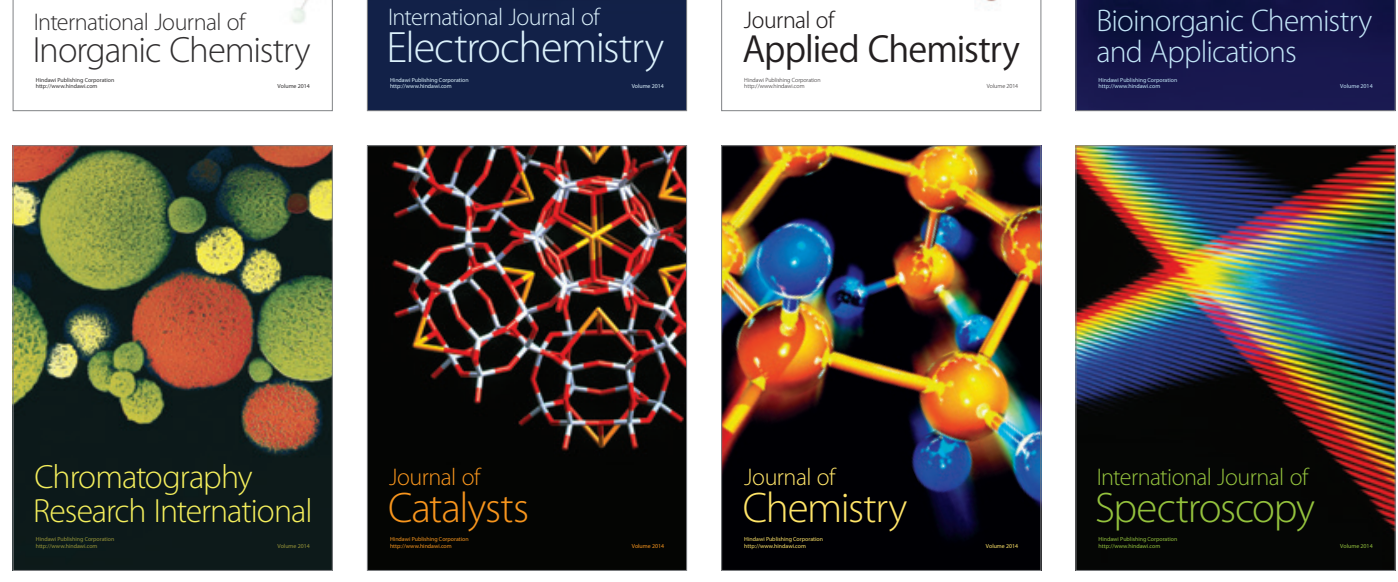